BNL-NUREG-72135-2004-CP

\title{
Seismic Response Prediction of NUPEC's Field Model Tests of NPP Structures with Adjacent Building Effect
}

\author{
J. Xu ${ }^{1)}$, C. Costantino ${ }^{1)}$, C. Hofmayer ${ }^{1)}$, S. Ali ${ }^{2)}$ \\ 1) Brookhaven National Laboratory, Upton, New York 11973-5000, USA \\ ${ }^{2)}$ U.S. Nuclear Regulatory Commission, Washington, D.C. 20555-0001, USA
}

\begin{abstract}
As part of a verification test program for seismic analysis computer codes for Nuclear Power Plant (NPP) structures, the Nuclear Power Engineering Corporation (NUPEC) of Japan has conducted a series of field model tests to address the dynamic cross interaction (DCI) effect on the seismic response of NPP structures built in close proximity to each other. The program provided field data to study the methodologies commonly associated with seismic analyses considering the DCI effect. As part of a collaborative program between the United States and Japan on seismic issues related to NPP applications, the U.S. Nuclear Regulatory Commission sponsored a program at Brookhaven National Laboratory (BNL) to perform independent seismic analyses which applied common analysis procedures to predict the building response to recorded earthquake events for the test models with DCI effect.
\end{abstract}

In this study, two large-scale DCI test model configurations were analyzed: 1) twin reactor buildings in close proximity and 2) adjacent reactor and turbine buildings. This paper describes the NUPEC DCI test models, the BNL analysis using the SASSI 2000 program, and comparisons between the BNL analysis results and recorded field responses. To account for large variability in the soil properties, the conventional approach of computing seismic responses with the mean, mean plus and minus one-standard deviation soil profiles is adopted in the BNL analysis and the three sets of analysis results were used in the comparisons with the test data. A discussion is also provided in the paper to address 1) the capability of the analysis methods to capture the DCI effect, and 2) the conservatism of the practice for considering soil variability in seismic response analysis for adjacent NPP structures.

\section{INTRODUCTION}

It is widely recognized that multiple structures built in close proximity exhibit different dynamic behaviors from those of a single structure under earthquake ground motions. With multiple structures involved, the dynamic cross interaction (DCI) effect through soils becomes a much more complex phenomenon. As part of a verification test program for seismic analysis computer codes for Nuclear Power Plant (NPP) structures, the Nuclear Power Engineering Corporation (NUPEC) of Japan has conducted a series of field model tests to address the DCI effect on the seismic response of NPP structures built in close proximity to each other. The field test consisted of large-scale DCI models with dynamic characteristics similar to typical NPP structures constructed on the soils representative of actual NPP sites [Suzuki, et al., 1999; Kitada, et al., 2001]. Seismometers installed on the test models have recorded responses to numerous earthquake motions experienced at the site during the period from 1994-1999.

As part of a collaborative program between the United States and Japan on seismic issues related to NPP applications, the U.S. Nuclear Regulatory Commission (NRC) sponsored a program at Brookhaven National Laboratory (BNL) to perform independent prediction of the seismic response of these DCI test models and compare the analytical response with the respective recorded data. It is the objective of this study to: 1) gain valuable insights into understanding the complex phenomena and dynamic response mechanism of DCI effects under earthquake ground motions and 2) determine the DCI effect using the methodologies commonly associated with seismic analyses of NPP structures and relevant regulatory guidelines. This paper summarizes the BNL analysis for predicting the NUPEC field tests with the DCI effect, and provides a discussion to address the methodologies commonly employed for seismic analyses of NPP structures. This study is part of a comprehensive effort by BNL [Xu, et al., 2003] to provide independent assessment of the seismic field test data provided by NUPEC.

The paper is organized in four sections. Following this introduction, Section 2 provides a description of the NUPEC field test models for the DCI effect. The BNL approach and the analysis models utilized for predicting the test data are summarized in Section 3. Section 4 provides a discussion on the comparison between the BNL analytic prediction of the seismic response of the test DCI models and the recorded data, and a discussion on the potential DCI effect on the applied methodology. Finally, conclusions are drawn in Section 5.

\section{DESCRIPTION OF NUPEC DCI TEST MODELS}

The NUPEC test site for the field tests was located in Aomori Prefecture in northern Japan, a region which experiences frequent seismic activities. Large-scale models with dynamic characteristics similar to typical NPP structures were constructed on soils representative of actual NPP sites [Kitada, et al., 2001]. The DCI field test models included two building configurations: a) closely spaced twin reactors and b) a reactor and a turbine building in close proximity to each other. The field tests also consider both excavated and embedded foundations. The tests were performed by pre-installed seismometers in the structures and free field, which have recorded numerous earthquakes during the period from 19941999. 
Figure 1 shows a layout of the NUPEC field test models. There are two structurally distinct model buildings involved in the test, namely, the reactor building and the turbine building in excavated and embedded conditions. The reactor building is a three-story reinforced concrete structure (1/10th scale of the typical reactor building in a commercial NPP in Japan). The building has dimensions of $8 \mathrm{~m}$ by $8 \mathrm{~m}$ in plane and $10.5 \mathrm{~m}$ in height and weighs about 660 metric tons. The turbine building is a two-story reinforced concrete structure and is $6.4 \mathrm{~m}$ by $10 \mathrm{~m}$ in plan and $6.75 \mathrm{~m}$ high and weighs about 395 metric tons. In addition, a single reactor building was constructed and instrumented for reference purpose. For the embedded configuration, the reactor building is embedded in soils about $5 \mathrm{~m}$ below ground surface, while the turbine building is embedded about $4 \mathrm{~m}$ in soil below ground surface. The twin-reactor buildings are situated in the north-south direction with a gap of $0.6 \mathrm{~m}$ between the two reactor buildings. The reactor-turbine buildings are also situated in the north-south direction with a gap of $0.1 \mathrm{~m}$ between the reactor and the turbine buildings, and are located to the north of the twin reactor buildings.

Three earthquakes (Nos. 157, 164 and 172) [Suzuki, et al., 2001] were used in this study. Earthquake No. 157 was recorded before the soil excavation for the DCI model structures was backfilled, while Earthquake No. 164 and No. 172 were recorded after the DCI model structures were embedded. The x-component of these earthquakes, which is in the north-south direction, is used in this study.

\section{DESCRIPTION OF THE BNL APPROACH AND ANALYSIS MODELS}

The BNL study consisted of two parts: 1) free-field analysis, and 2) SSI response analysis. The free-field analysis determines the strain dependent soil profiles and the surface input motions for the SSI response analyses. BNL applied the current practice for performing free-field analyses and correlated the analytical results with the recorded free-field data provided by NUPEC to establish the mean soil profile and the corresponding free-field surface motion [Xu, et al., 2001 and 2002]. To account for soil variability, lower and upper bound profiles, which correspond to the mean minus sigma and mean plus sigma, were determined assuming a lognormal standard deviation of sigma $=0.2$ for the soil shear wave velocity. Three soil profiles were used in the SSI analysis which was performed using the sub-structuring subtraction method as implemented in the SASSI2000 program. The SASSI2000 program was developed by Lysmer and his team at U.C. Berkeley [Lysmer, et al., 1981 and 1999].

In the SASSI models of the reactor and the turbine buildings, the portions of the structure below the ground surface were modeled with explicit finite elements (e.g., 3-D bricks and shells), while the superstructures above the ground surface were modeled with simple lumped masses and 3-D beams. Figure 2 shows the SASSI model of the excavated reactor-turbine configuration. Due to the symmetric configuration of the structure, only half of the structure was modeled with the plane $\mathrm{y}=0$ (east-west direction) as the symmetry plane. As shown in this figure, the basemat was modeled with brick elements and the sidewalls and internals were modeled with shell elements. The superstructure was modeled with lumped masses and beams. The base of the superstructure is connected to the sidewalls by rigid links to simulate the rigid diaphragm of the floor at grade level. Also as indicated in the figure, a thin layer of soil elements was added underneath the basemat to account for the softening effect induced by the excavation activities. A nominal shear wave velocity of $150 \mathrm{~m} / \mathrm{s}$ was assigned to the thin layer of soil based on the data provided by NUPEC. In order to apply the subtraction method, the nodes at the boundary of the excavation need to be identified as the interaction nodes and the volume of the excavated pit were modeled using brick elements in the SASSI model.

For the embedded configuration, the building models are the same as those for the excavated condition. The soils between the structures were modeled using brick elements, as shown in Figure 3 for the embedded reactor-turbine configuration. Since the twin reactor configuration has two identical structures, a quarter-model was developed, as depicted in Figure 4 for the embedded twin reactor configuration.

\section{DISCUSSION OF POTENTIAL DCI EFFECT BY COMPARISON OF BNL ANALYSIS WITH RECORDED DATA}

The purpose of this study is to 1) assess the significance of the potential DCI effect on seismic response, 2) evaluate the adequacy of the methodology for capturing the DCI phenomenon, and 3) assess the DCI effect on the overall methodology and regulatory guidelines for performing the SSI analysis. This section provides a discussion on the DCI effect based on comparisons using both recorded data and the SASSI analysis results. The SASSI analysis was performed considering the soil uncertainty in terms of the mean, mean plus/minus sigma soil profiles. The response parameters used for the comparisons are response spectra at the center of the basemat and the center of the roof of respective structures. In order to isolate the DCI effect, both the recorded and the analysis responses are compared in terms of the spectral ratios which are done by dividing spectral amplitudes for the respective twin reactor and reactor-turbine cases by those computed from the reference single reactor for both the embedded and excavated site conditions. Therefore, it can be interpreted that, for the spectral ratios higher than unity, the DCI effect results in amplified response, while if the spectral ratios are smaller than unity, the DCI effect gives rise to a reduction of the structural response.

Figures 5 and 6 present comparisons of the spectral ratios at the basemat and the roof for the excavated twin reactors subject to Earthquake No. 157. The primary frequency range is between about 4 to $10 \mathrm{~Hz}$. As shown in these figures, for the frequency range of interest, the recorded spectral ratios are mostly higher than unity while the computed mean plus/minus sigma results are mostly lower than unity except for the computed mean spectral ratios which are higher than the recorded spectral ratios. These comparisons indicate that for the frequency range of dominant responses, there is no good tracking of correlations between 
computed and recorded DCI effects. However, when the soil uncertainty is appropriately treated in the SSI analysis, the spectral ratios computed from three soil profiles together generally envelope the recorded ratio for the excavated twin reactor configuration. For the reactor-turbine (R-T) configuration, due to the different elevations to which the reactor and turbine structures were situated, the basemat of the reactor building was embedded one meter into soil. The reactor buildings in the single and the twin configurations did not include such embedment. Therefore, the R$\mathrm{T}$ reactor would exhibit the response peaks shifting to higher frequencies due to the $1 \mathrm{~m}$ embedment compared to the single reactor response. The DCI effect in this case as exhibited in Figure 7 may have exaggerated the amplified spectral ratio near $9 \mathrm{~Hz}$. This is further substantiated by the comparison of the recorded response spectra in Figure 8 where the frequency shift is clearly illustrated.

For the fully embedded configuration, Figures 9 through 12 present comparisons of both recorded and computed responses for Earthquake No. 164, while Figures 13 and 14 provide response comparisons for Earthquake No. 172. For the fully embedded configuration, the recorded spectral peak frequency is about $9 \mathrm{~Hz}$. Near this frequency, the spectral ratio of the recorded response shows generally lower than unity, which means that the DCI effect reduces the peak response. Again, the computed spectral ratios do not show good correlation of DCI effect with the recorded data, even though the computed results show higher spectral ratios near the spectral peak.

Another general observation from these comparisons of recorded responses is that, for the same earthquake input, the magnitudes of the differences in spectra between the single reactor and the other two configurations with adjacent structures tend to be larger for the excavated structural condition as compared to the fully embedded condition. Further, the DCI effect may not always lead to reduction of the response; in fact, as noted in many of the comparisons discussed above, amplified responses were observed due to the DCI effect. However, it appears consistent that the DCI effect always leads to reduction near the dominant peak of the response spectra, which perhaps is most important in designs.

\section{CONCLUSIONS}

This study was performed to assess the significance of the potential DCI effect on seismic response. The DCI effect was investigated by examining the ratios of the response spectral values of the model reactors with and without the DCI effect. The SSI methodology applied in the nuclear industry was evaluated by comparing the analysis results computed using the SASSI program to recorded data. Based on the BNL analyses and comparisons between the analysis results and the recorded earthquake responses, the following conclusions with respect to the DCI effect are drawn:

1. Based on the examination of spectral ratios from recorded data, Dynamic Cross Interaction (DCI) effects were observed to be important. For the earthquake data studied, some showed that the DCI effects cause amplification of the structural response with respect to the single reactor configuration, while others suggested a reduction of response when compared with the single reactor configuration. Further, the analytic results generally showed conservative estimates of the DCI effect near the peak responses when considering soil uncertainty in the calculations.

2. The impact on the seismic response due to the DCI effect was lower for the fully embedded configuration as compared to the excavated configuration.

3. The calculated SSI responses do not adequately render good correlation with recorded data with respect to DCI effects. However, when soil uncertainties are considered, the computed SSI analyses tend to over estimate the DCI effect at or near peak spectral responses.

The inadequate characterization of the DCI effect in the SSI analysis should be further investigated. Certain influences of the DCI effect on the SSI calculations may be associated with inherent uncertainties in structural properties which may not be adequately captured by the analytical models. Small uncertainty in the analytical modeling parameters (mass, cg location, etc.) may need to be introduced into the analysis to determine the impact of the structural modeling on the DCI effect.

\section{DISCLAIMER NOTICE}

This work was performed under the auspices of the U.S. Nuclear Regulatory Commission, Washington, D.C. The findings and opinions expressed in this paper are those of the authors, and do not necessarily reflect the views of the U.S. Nuclear Regulatory Commission or Brookhaven National Laboratory.

\section{REFERENCES}

Kitada, Y., et al., 2001, "Model Test on Dynamic Cross Interaction of Adjacent Buildings in Nuclear Power Plants Overview and Outline of Earthquake Observation in the Field Test," Trans. 16th SMiRT, Session K10/5, Washington DC.

Lysmer, J., et al., 1981, "SASSI - A System for Analysis of Soil-Structure Interaction," Report No. UCB/GT/81-02, Geotechnical Engineering, University of California, Berkeley.

Lysmer, J., et al., 1999, "SASSI2000 - Theoretical Manual," Revision 1, Geotechnical Engineering, University of California, Berkeley.

Suzuki, A. et al., 2001, "Evaluation of Seismic Input Motions and Responses of Buildings in Nuclear Power Plants," Proceeding of the OECD/NEA Workshop on the Engineering Characterization of Seismic Input, Brookhaven National Laboratory, Upton, New York, NEA/CSNI/R(2000)2/Volume 2.

$\mathrm{Xu}$, J., et al., "Identification Of Free-Field Soil Properties Using NUPEC Recorded Ground Motions," SMiRT-16, Washington, D.C., August 12-17, 2001. 
Xu, J., et al., 2002, "Probabilistic Site Identification Analysis Using NUPEC Recorded Free-Field Motions," ASME - PVP, Vancouver, CA.
$\mathrm{Xu}$, J., et al., 2003 "Collaborative Study of NUPEC Seismic Field Test Data for NPP Structures," NUREG/CR-6822. 


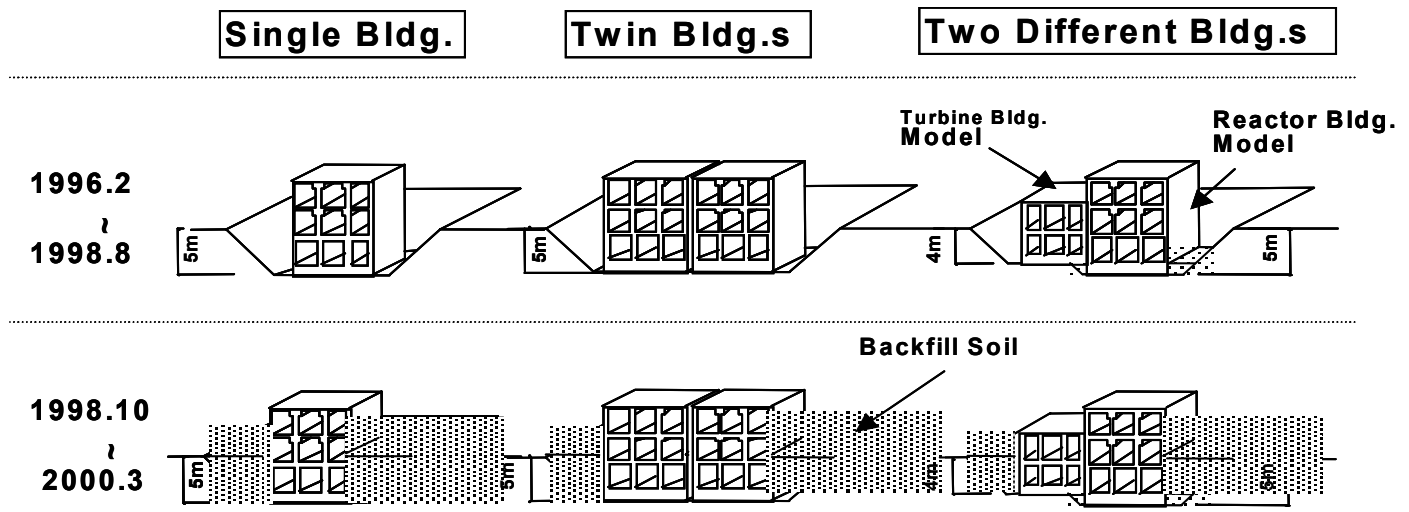

Figure 1. Layout of NUPEC Field Test Models.

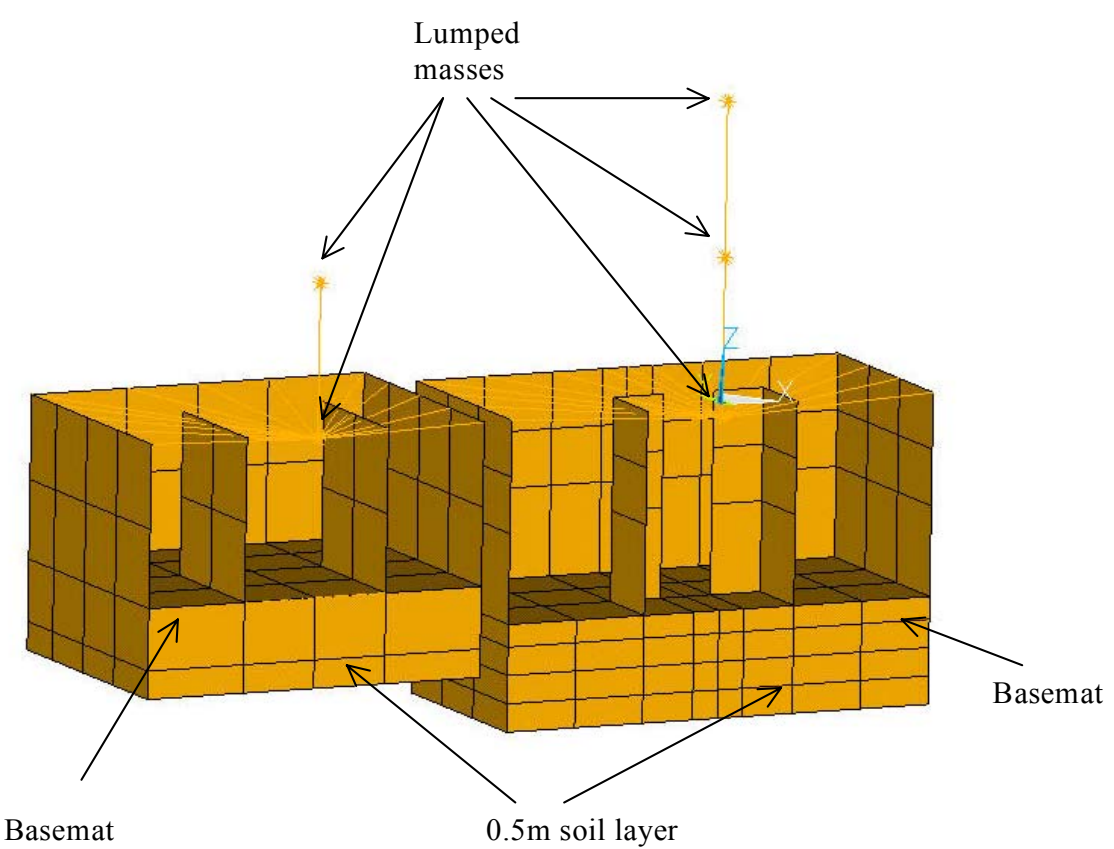

Figure 2. BNL SASSI Model of the Excavated Reactor-Turbine Buildings. 


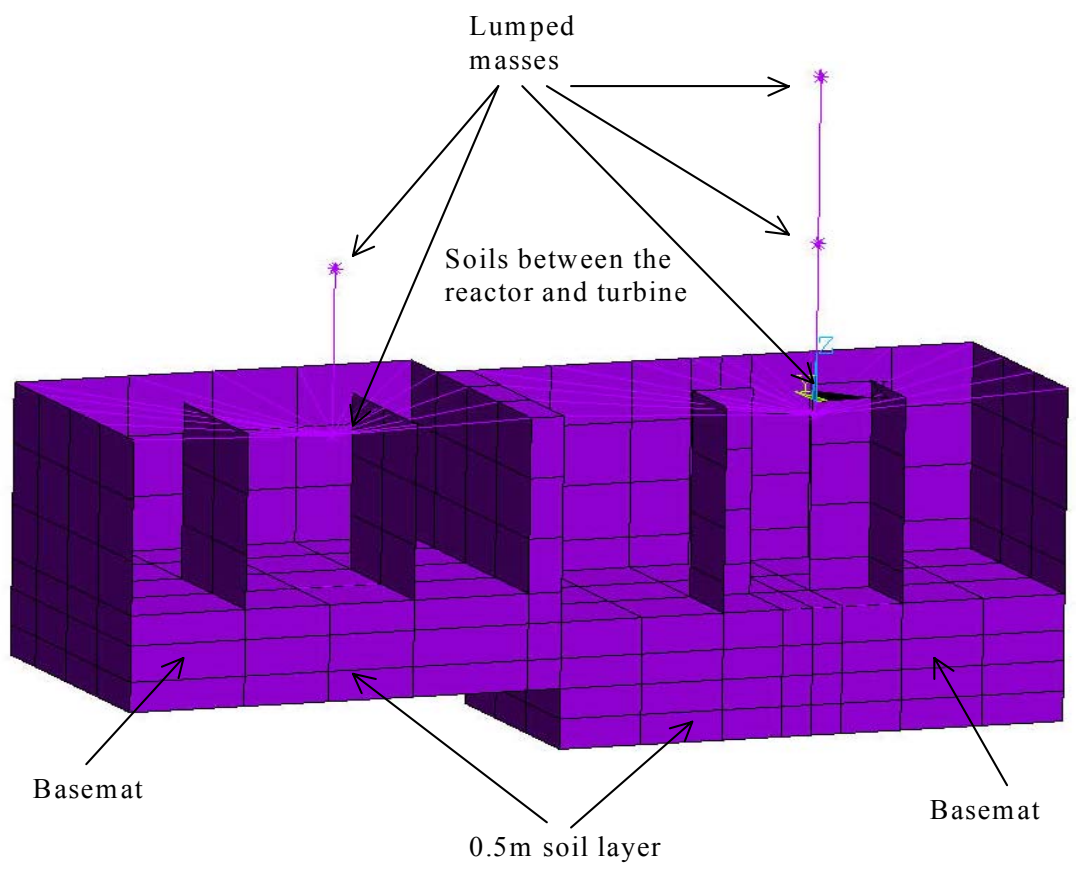

Figure 3. BNL SASSI Model of the Embedded Reactor-Turbine Buildings.

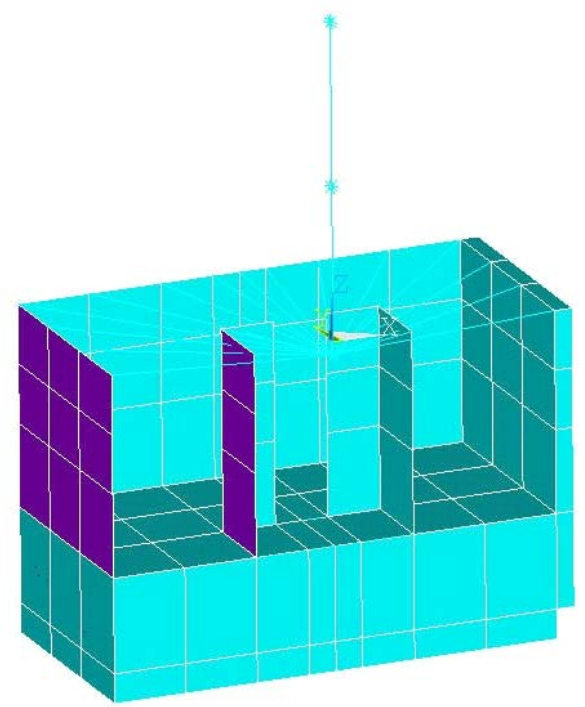

Figure 4. BNL SASSI model of the embedded twin-reactor buildings. 


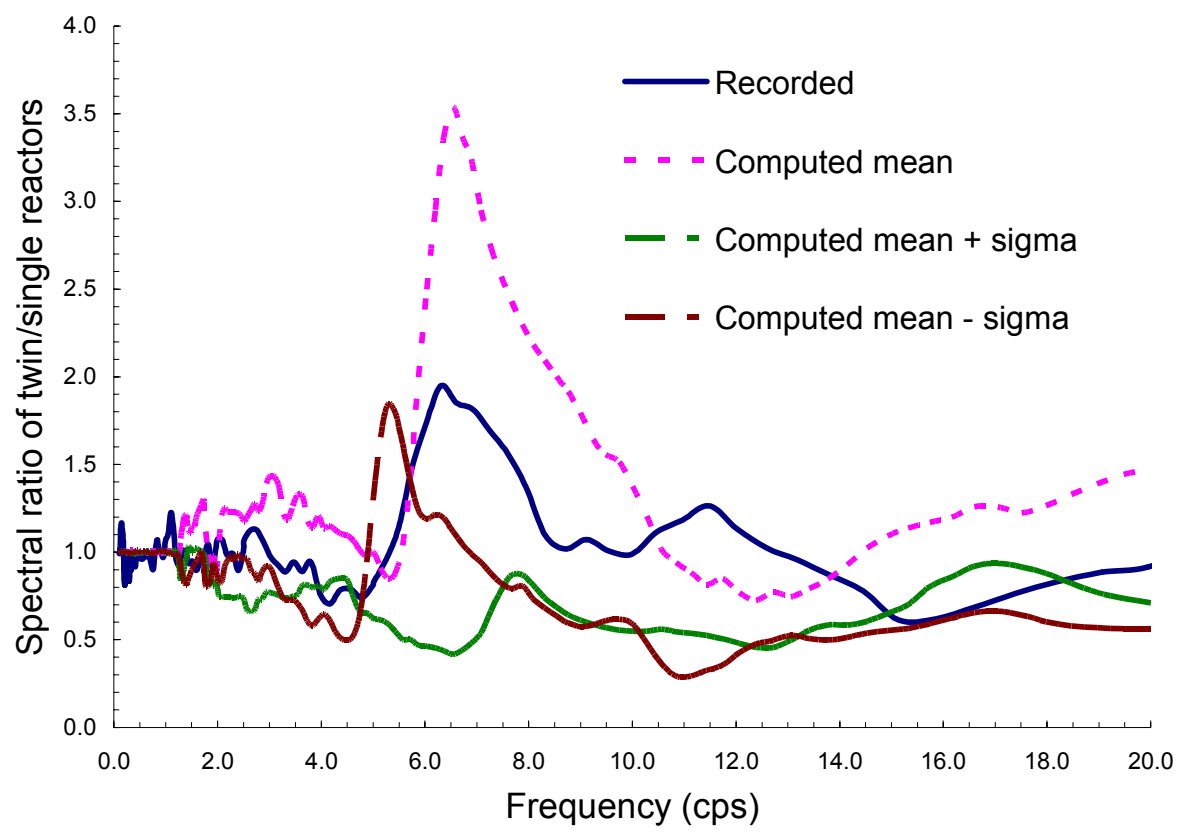

Figure 5. Comparison of DCI effect at basemat of excavated Twin Reactor for Earthquake 157.

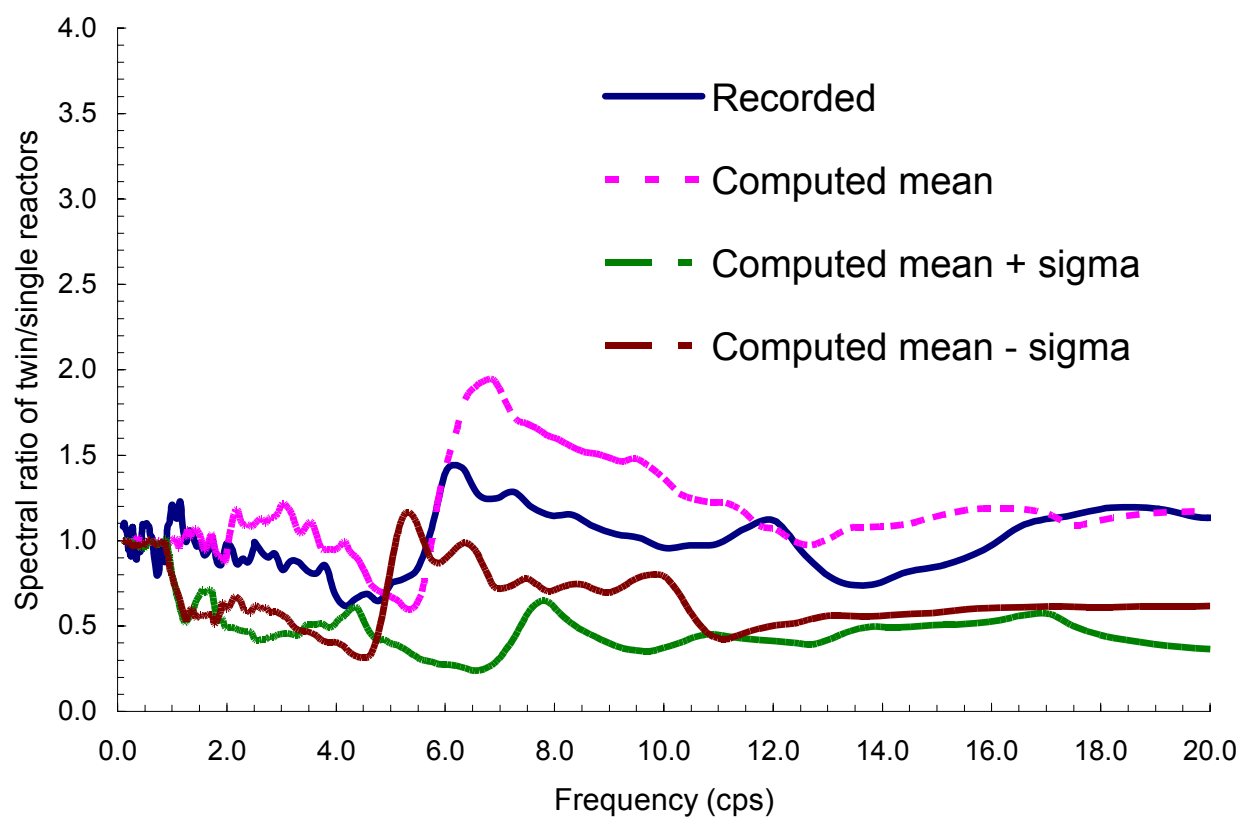

Figure 6. Comparison of DCI effect at roof of excavated Twin Reactor for Earthquake 157. 


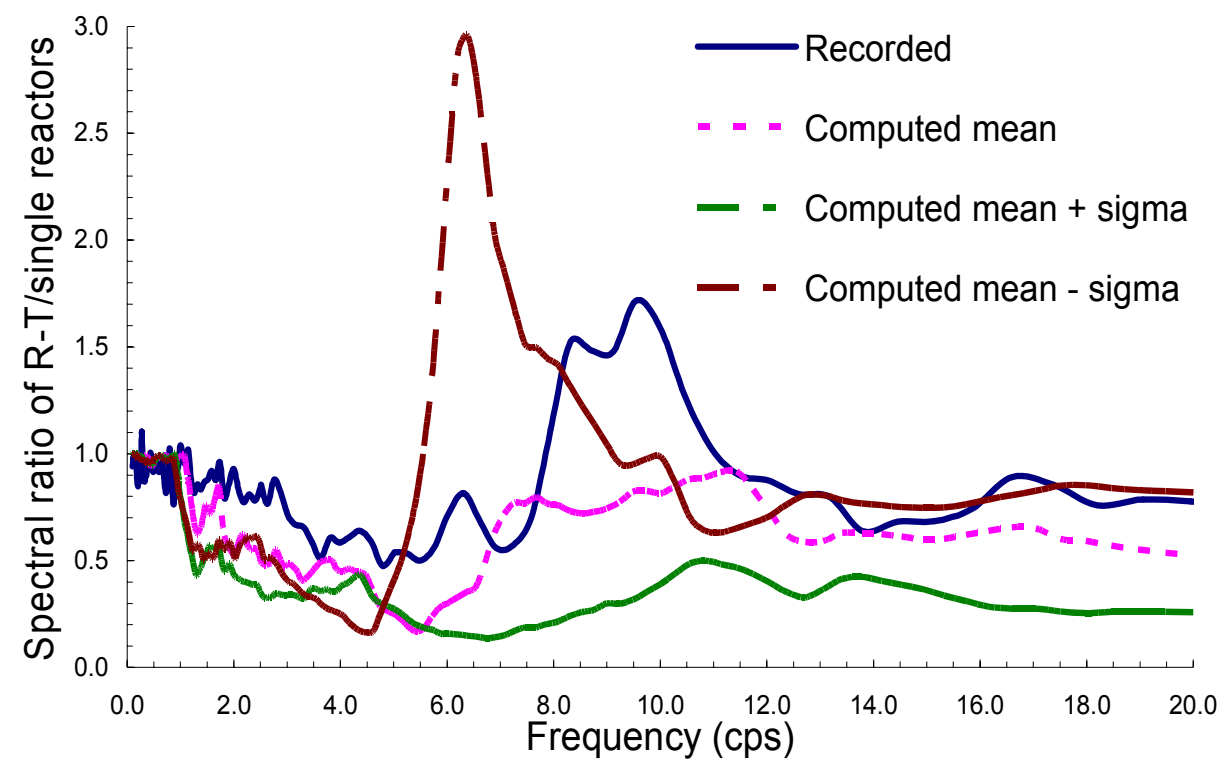

Figure 7. Comparison of DCI effect at roof of excavated R-T Reactor for Earthquake 157.

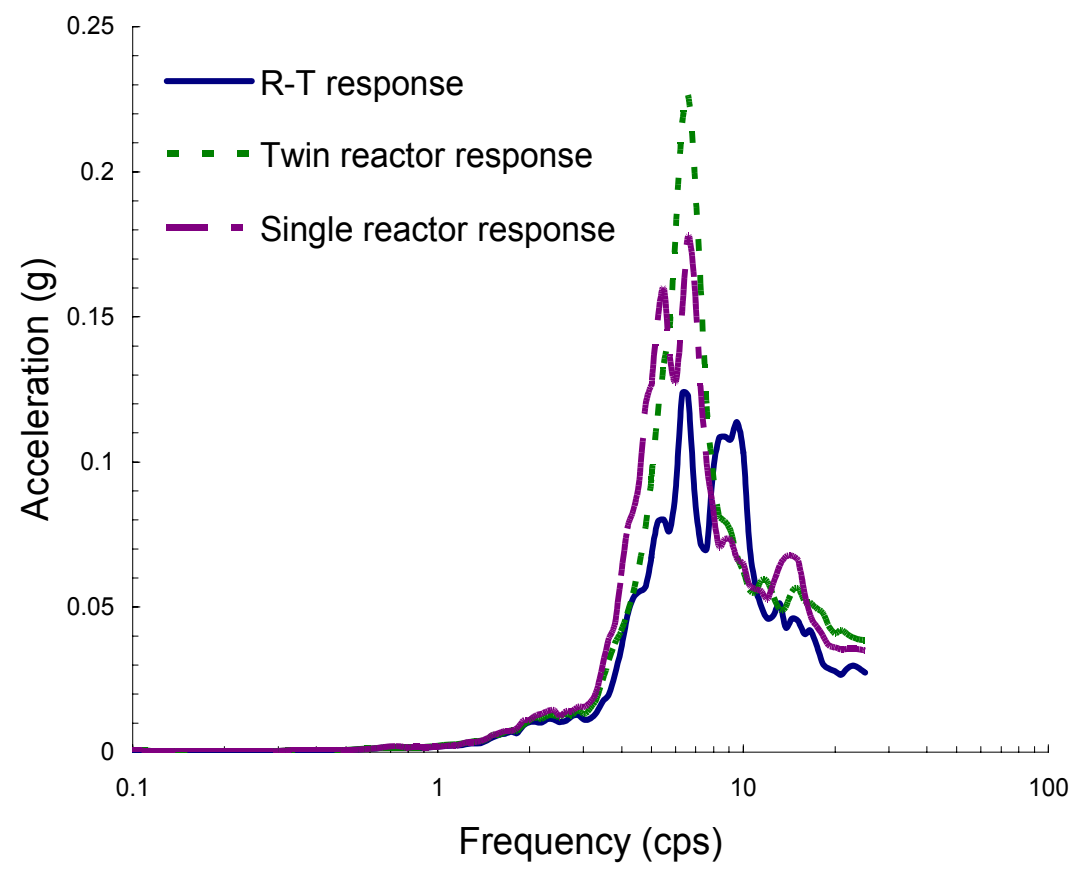

Figure 8. Comparison of the recorded responses at the roof of excavated configurations for Earthquake 157. 


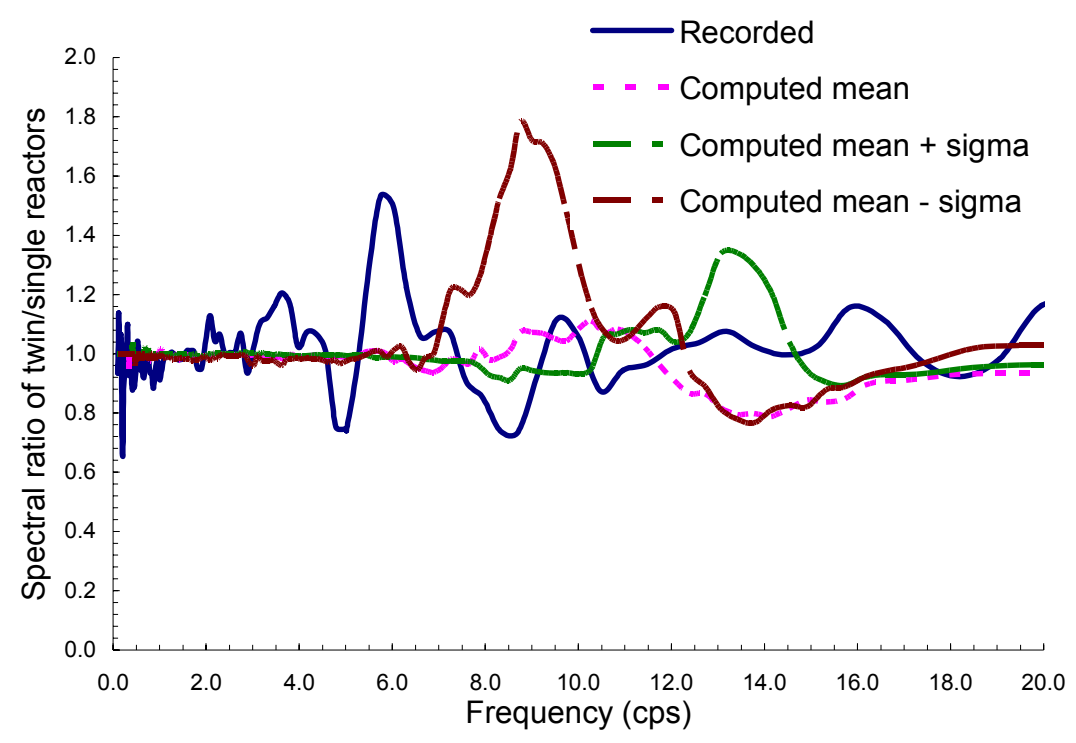

Figure 9. Comparison of DCI effect at basemat of embedded Twin Reactor for Earthquake 164.

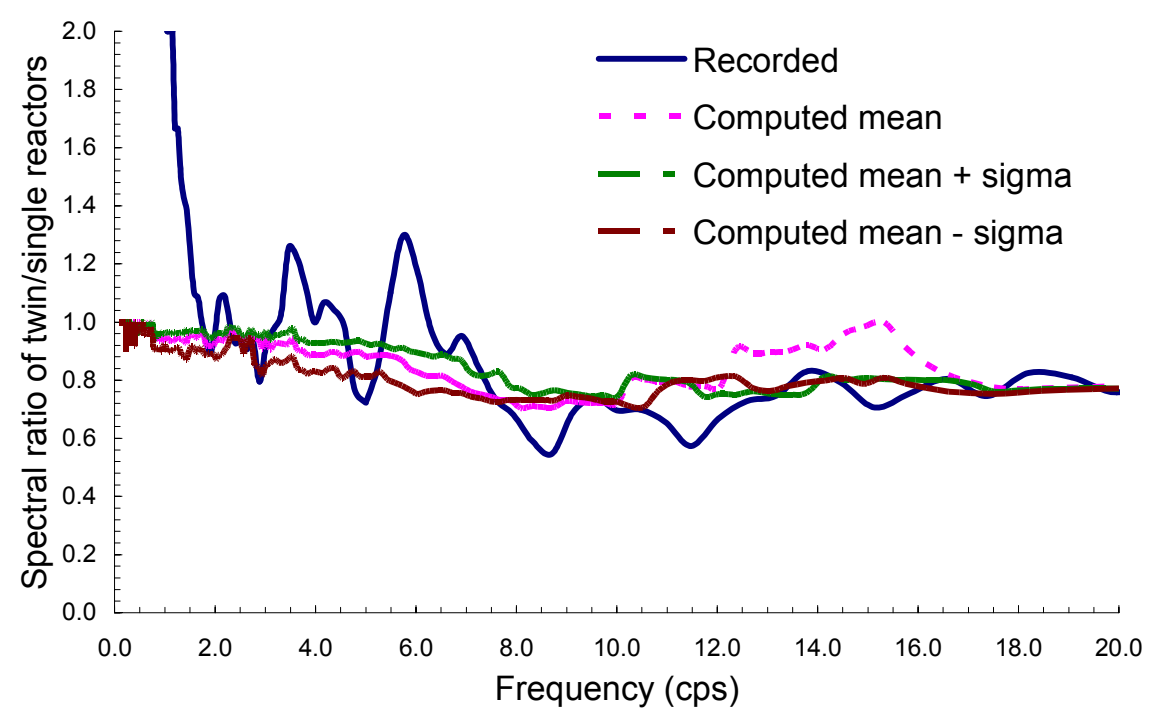

Figure 10. Comparison of DCI effect at roof of embedded Twin Reactor for Earthquake 164. 


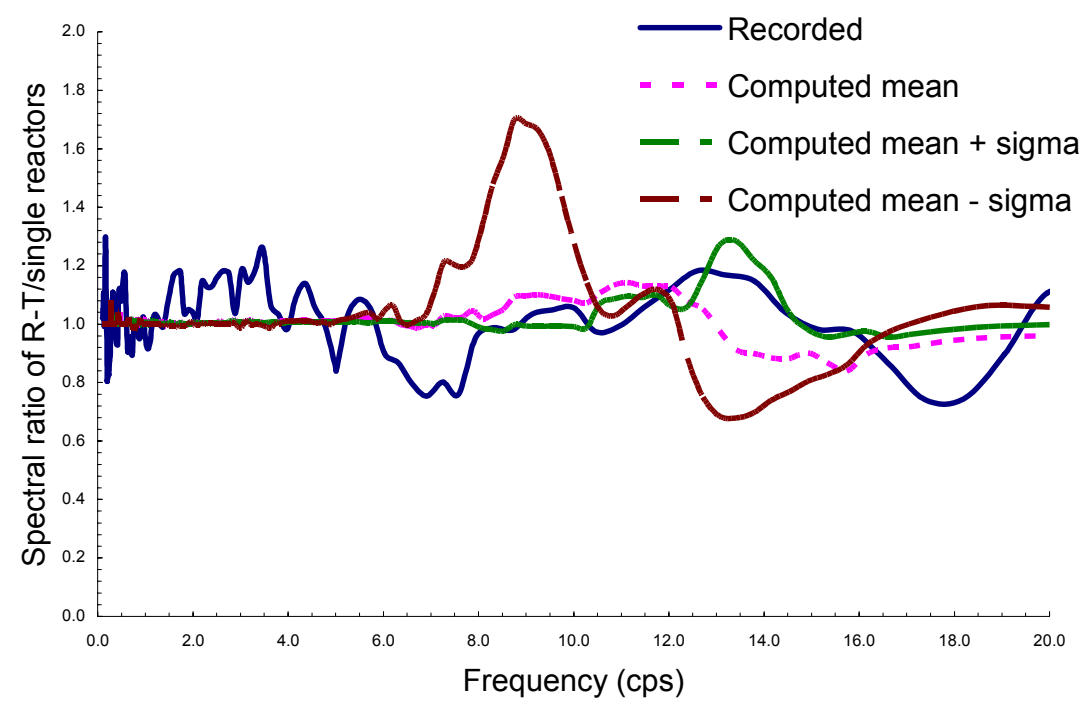

Figure 11. Comparison of DCI effect at basemat of embedded R-T Reactor for Earthquake 164.

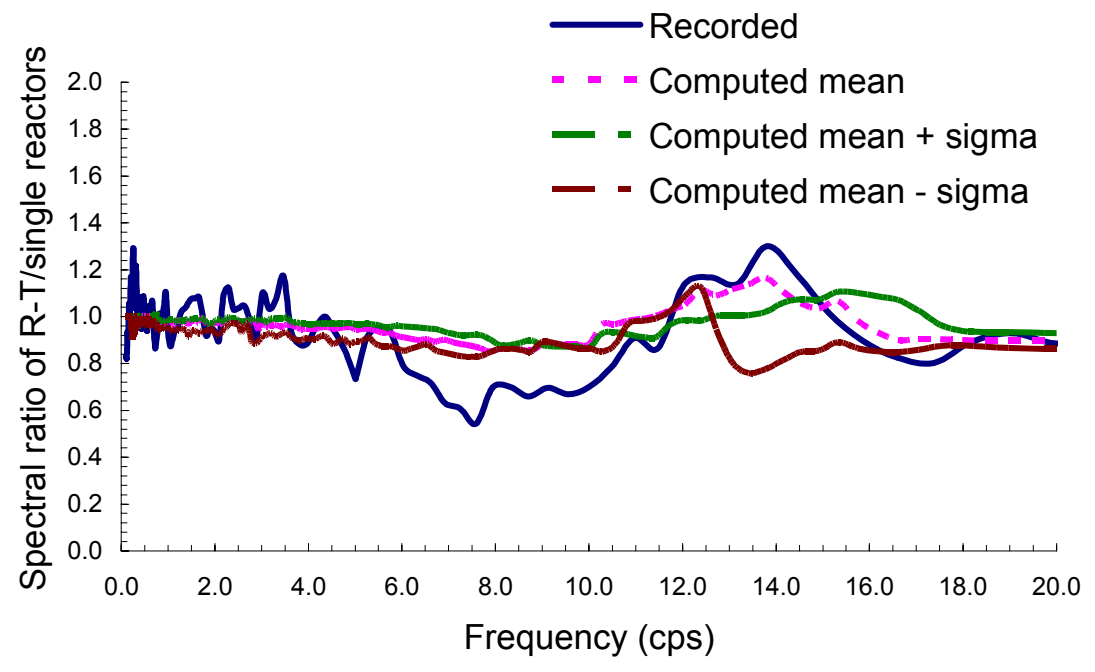

Figure 12. Comparison of DCI effect at roof of embedded R-T Reactor for Earthquake 164. 


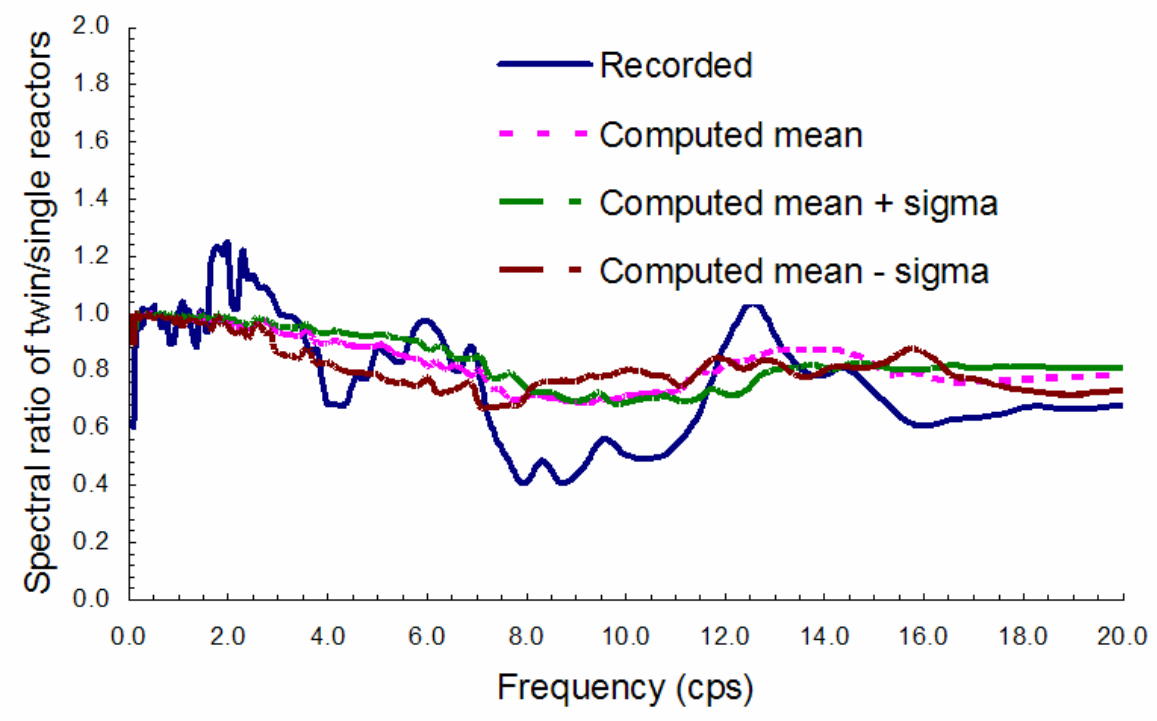

Figure 13. Comparison of DCI effect at roof of embedded Twin Reactor for Earthquake 172.

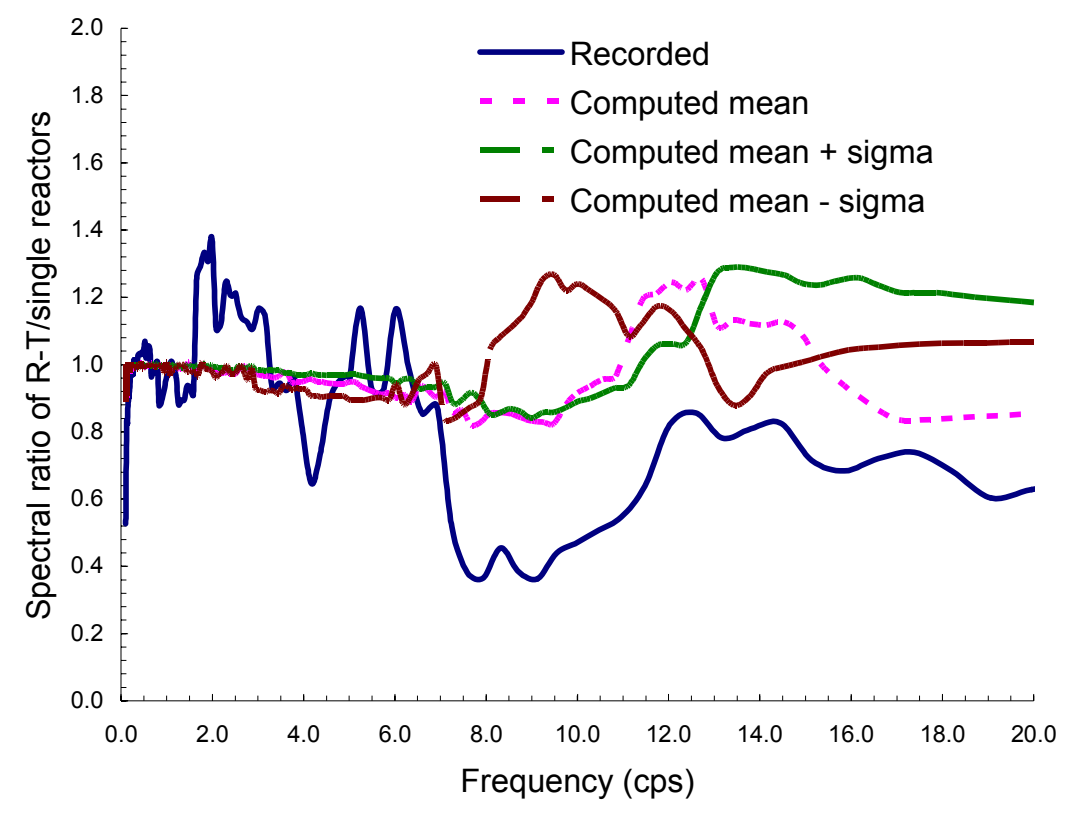

Figure 14. Comparison of DCI effect at roof of embedded R-T Reactor for Earthquake 172. 